Article

\title{
Discovery of a Natural Product That Binds to the Mycobacterium tuberculosis Protein Rv1466 Using Native Mass Spectrometry
}

\author{
Ali R. Elnaas ${ }^{1}$, Darren Grice ${ }^{2}$, Jianying Han ${ }^{1}{ }^{1}$, Yunjiang Feng ${ }^{1}$, Angela Di Capua ${ }^{1}$, Tin Mak ${ }^{1}$, \\ Joseph A. Laureanti ${ }^{3}$, Garry W. Buchko ${ }^{4,5}$, Peter J. Myler ${ }^{6}$, Gregory Cook ${ }^{7}$ (D), \\ Ronald J. Quinn ${ }^{1}$ (D) and Miaomiao Liu ${ }^{1, *(D)}$ \\ 1 Griffith Institute for Drug Discovery, Griffith University, Brisbane, Queensland 4111, Australia; \\ ali.elnaas@griffithuni.edu.au (A.R.E.); jianying.han@griffithuni.edu.au (J.H.); y.feng@griffith.edu.au (Y.F.); \\ a.dicapua@griffith.edu.au (A.D.C.); t.mak@griffith.edu.au (T.M.); r.quinn@griffith.edu.au (R.J.Q.) \\ 2 Institute for Glycomics, Griffith University, Gold Coast, Queensland 4222, Australia; d.grice@griffith.edu.au \\ 3 Physical and Computational Sciences Directorate, Pacific Northwest National Laboratory, \\ Richland, WA 99354, USA; joseph.laureanti@pnnl.gov \\ 4 Earth and Biological Sciences Directorate, Pacific Northwest National Laboratory, Richland, WA 99354, USA; \\ garry.buchko@pnnl.gov \\ 5 School of Molecular Biosciences, Washington State University, Pullman, WA 99164, USA \\ 6 Center for Global Infectious Disease Research, Seattle Children's Research Institute, Seattle, WA 98109, USA; \\ peter.myler@seattlechildrens.org \\ 7 Department of Microbiology and Immunology, University of Otago, Dunedin 9016, New Zealand; \\ greg.cook@otago.ac.nz \\ * Correspondence: miaomiao.liu@griffith.edu.au; Tel.: +61-7-3735-6077
}

Academic Editors: Elisa Ovidi and Antonio Tiezzi

Received: 25 April 2020; Accepted: 18 May 2020; Published: 21 May 2020

\begin{abstract}
Elucidation of the mechanism of action of compounds with cellular bioactivity is important for progressing compounds into future drug development. In recent years, phenotype-based drug discovery has become the dominant approach to drug discovery over target-based drug discovery, which relies on the knowledge of a specific drug target of a disease. Still, when targeting an infectious disease via a high throughput phenotypic assay it is highly advantageous to identifying the compound's cellular activity. A fraction derived from the plant Polyalthia sp. showed activity against Mycobacterium tuberculosis at $62.5 \mu \mathrm{ge} / \mu \mathrm{L}$. A known compound, altholactone, was identified from this fraction that showed activity towards $M$. tuberculosis at an minimum inhibitory concentration (MIC) of $64 \mu \mathrm{M}$. Retrospective analysis of a target-based screen against a TB proteome panel using native mass spectrometry established that the active fraction was bound to the mycobacterial protein Rv1466 with an estimated pseudo- $K_{\mathrm{d}}$ of $42.0 \pm 6.1 \mu \mathrm{M}$. Our findings established Rv1466 as the potential molecular target of altholactone, which is responsible for the observed in vivo toxicity towards $M$. tuberculosis.
\end{abstract}

Keywords: altholactone; tuberculosis; Rv1466; drug target; native mass spectrometry

\section{Introduction}

Tuberculosis (TB) is the leading cause of death by an infectious agent worldwide, claiming an estimated 1.3 million lives in 2018, with an estimated 10 million people becoming ill with the disease [1]. The etiological agent responsible for TB is Mycobacterium tuberculosis $(M t b)$, an airborne bacterial pathogen. Humans are the only known reservoir for $M t b$, where a complex mechanism has evolved that allows the pathogen to survive and replicate within macrophages and maintain a life-long latency within the host [2]. While modern public health care systems and effective drug treatment programs 
have made TB "invisible" for the most part in North America and Western Europe, the emergence of multidrug and extremely drug-resistant strains of $M t b$ could allow the disease to return to this part of the world with a vengeance [3]. In 2018, there were half a million new cases of rifampicin-resistant $M t b$, of which $78 \%$ were multidrug-resistant TB [1]. Consequently, there is an urgency to develop new intervention therapies to keep ahead of the disease.

A rich potential resource for the development of new intervention strategies against TB and other infectious diseases are natural products $[4,5]$. Since ancient times, drugs derived from natural sources have been employed to treat diseases and ailments. Recently there has been a return to natural products for lead compound identification [6-8]. Natural products are largely secondary metabolites with small molecular weights extracted from other living organisms. The wide diversity of life under different environments provides a chemical diversity of low molecular weight compounds that do not exist in comparison to standard combinatorial organic chemistry. Given that less than $10 \%$ of nature has been evaluated for medicinal properties, natural products represent a large under-explored reservoir for drug discovery [9]. As this reservoir is rapidly shrinking due to human activities, such as poor land management [10], war [11], and global warming [12], reducing the biodiversity on our planet [13], there is an urgency to harness these natural resources for medical purposes before they disappear.

In contrast to the large number of compounds isolated from nature, the number of these compounds whose target molecules have to date been identified is limited. Elucidation of the mechanism of action of bioactive natural products that show antimicrobial activity towards infectious diseases is an important but challenging field [14]. At the same time, this is the major bottleneck for drug development of synthetic compounds identified in phenotype-based screening. Over the years, several new target identification strategies have been developed and the number of successful examples is steadily growing [15]. Furthermore, in the case of natural product drug discovery, the additional challenge is low compound availability, limiting the use of some target identification strategies.

\section{Results}

In this work, we used both phenotype-based screening and target-based screening to sequentially identify a low molecular weight compound with phenotypic activity along with the potential molecular target of the molecule (Figure 1). Identifying a putative protein target allows the initiation of a target validation campaign to understand the underlying mechanism of action [16]. With regards to targets with uncharacterized/unannotated functions, ligand identification can be a vital first step towards decoding the biochemical function because the identified ligand and natural substrate might share functional groups or structural features [17]. In this study, phenotypic activity was identified through high throughput screening of a natural product fraction library against $M$. tuberculosis. Library fractions with favorable phenotypic activity were then screened against a panel of purified putative M. tuberculosis targets. This was achieved with native mass spectrometry screening employing electrospray ionization magnetic resonance mass spectrometry (MRMS) [18,19]. A crude estimation of the ligand's dissociation constant, $K_{\mathrm{d}}$, with the target could be obtained by a mass spectrometry (MS) dose response curve.

A high-throughput screening (HTS) of fractions from plant species and marine organisms against $M t b$ identified a series of active fractions. Fraction 3 derived from the plant Polyalthia sp. showed anti-Mtb activity with an MIC value of $62.5 \mu \mathrm{ge} / \mu \mathrm{L}$. Further isolation and purification led to identification of a known compound, altholactone, with a molecular weight of $232 \mathrm{Da}$ (Figure 2A). Altholactone was first discovered from a Polyalthia species in 1977 [21]. Previous studies showed that altholactone exhibited antimycobacterial activity against the $M t b$ strains $\mathrm{H}_{37} \mathrm{Ra}$ and $M t b \mathrm{H}_{37} \mathrm{Rv}$, with MIC values of $6.25 \mu \mathrm{g} / \mathrm{mL}(26.9 \mu \mathrm{M})$ [22] and $32 \mu \mathrm{g} / \mathrm{mL}(137.9 \mu \mathrm{M})$ [23], respectively. In the present study, we extended these explorations to evaluate the antimycobacterial effect of altholactone against M. smegmatis mc $\mathrm{m}^{2} 155$ and $M t b \mathrm{mc}^{2} 6230$. As shown in Figure 2B, altholactone showed activity against $M$. smegmatis with an MIC value of $500 \mu \mathrm{M}$ (tested range 3-500 $\mu \mathrm{M}$ ). In addition, it showed activity against the $M t b$ strain $\mathrm{mc}^{2} 6230(\mathrm{MIC}=64 \mu \mathrm{M}$, tested range 4-512 $\mu \mathrm{M})$ that contained two deletions in the 9455-bp 
region of deletion 1 (RD1) of the protein in the pantothenate biosynthesis pathway, to render the organism non-pathogenic.

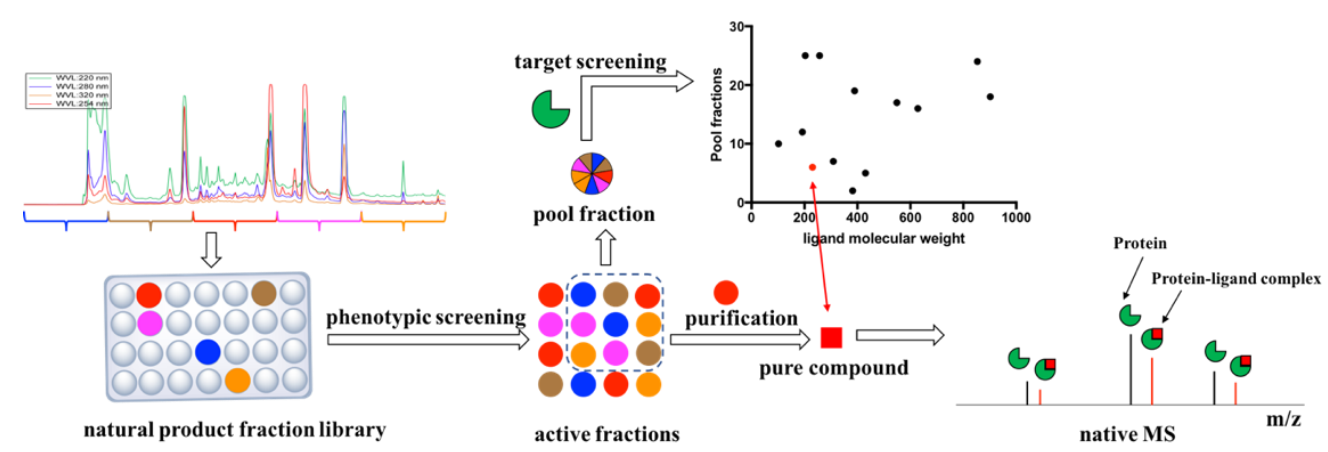

Figure 1. Overview of natural product drug discovery using both phenotypic screening and target screening approaches. A high throughput phenotypic screening of 202,983 Nature Bank (NB) lead-like enhanced (LLE) fractions [20] against $M$. tuberculosis $\mathrm{H}_{37} \mathrm{Rv}$ was initially performed. Active fractions were screened against a panel of 37 putative anti-tuberculosis (TB) targets from Mycobacteria species. To lower sample consumption, especially protein, nine active fractions were pooled (40 Pool Fractions) and incubated with each of the target proteins. The pooled fraction-protein mixtures were examined by native mass spectrometry to identify protein-ligand complexes. The mass shift between the protein (black) and the protein-ligand complex (red) peaks provided the molecular weight of the bound ligand.

A<smiles>O=C1C=C[C@H]2O[C@H](c3ccccc3)[C@@H](O)[C@H]2O1</smiles>

B

\begin{tabular}{ll}
\hline Mycobacteria strains & MIC \\
\hline Mtb strain mc $^{2} 6230$ & $64.0 \mu \mathrm{M}$ \\
\hline M. smegmatis $\mathrm{mc}^{2} 155$ & $500.0 \mu \mathrm{M}$ \\
\hline$M t b \mathrm{H}_{37} \mathrm{Ra}[22]$ & $26.9 \mu \mathrm{M}$ \\
\hline$M t b \mathrm{H}_{37} \mathrm{Rv}[23]$ & $137.9 \mu \mathrm{M}$ \\
\hline
\end{tabular}

Figure 2. (A) Structure of altholactone; and (B) biological activity of altholactone against Mycobacteria strains and species.

We have recently published a new natural product drug discovery approach 'PhenoTarget Drug Discovery', which combines phenotypic screening followed by target screening on the phenotypic active natural product fractions [24]. The objective was to identify compounds with cellular activities and also identify the molecular target. This approach could be equally applied to pure compound libraries as well as natural product fraction/extract libraries, due to the development of a highly sensitive and easy-to-perform target screening technique using cloned and purified proteins. The target identification component directly observes non-covalent and covalent protein-ligand complexes. A particular advantage of this method is that it requires no tag, e.g., a biotin or fluorescent tag to be added to the compounds or proteins. The rapid, label-free native MS approach depends on non-denaturing electrospray-ionization (ESI) to recognize multi-charged proteins in their near-native states. Due to the gentle conditions employed to spray the target in the native state it was possible to directly observe non-covalent and covalent protein-ligand complexes [25]. The difference between the mass-to-charge ratio $(\Delta m / z)$ for the protein-ligand complex and the unbound protein ions multiplied by the charge state $(z)$ directly provided the molecular weight of the bound ligand (hit) $\left(\mathrm{MW}_{\text {ligand }}=\Delta m / z \times z\right)$.

Retrospective analysis of native MS screening on 40 pool fractions combined with 362 hit fractions with anti- $M t b \mathrm{H}_{37} \mathrm{Rv}$ cellular activity against a panel of 37 purified putative mycobacterial drug targets was conducted. A pool fraction containing a "hit" fraction derived from Polyalthia sp. was identified as 
forming a protein-ligand complex with the $M t b$ protein Rv1466. As shown in Figure 3A, three charge states, 5+, 6+, and 7+ were observed for Rv1466, under the native MS conditions. As shown in Figure 3B, upon addition of the active pool fraction, the same three charged states were observed but all shifted to higher $\mathrm{m} / \mathrm{z}$. Using the dominant peak as an example, the molecular weight of the bound ligand was calculated to be $232.06 \mathrm{Da}((2462.35069-2423.67327) \times 6=232.06 \mathrm{Da})$, which was consistent with the covalent binding of the isolated compound altholactone (Figure 3B). Identification of altholactone was confirmed by the observation of the same mass spectrum using isolated pure altholactone and Rv1466 (Figure 3C).

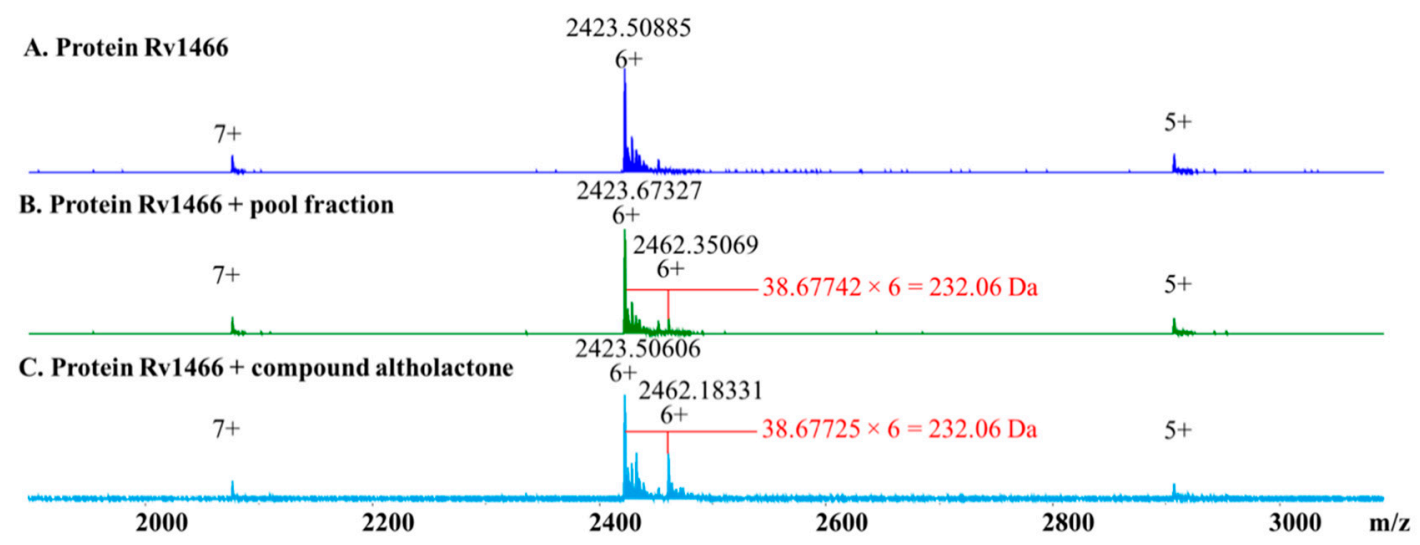

Figure 3. Native MS spectra of (A) Rv1466; (B) Rv1466 mixed with a pool fraction; and (C) Rv1466 mixed with pure isolated altholactone. The same binding ligand with molecular weight 232.06 Da was identified from both the pool fraction and pure compound altholactone.

Electrospray ionization-mass spectrometry (ESI-MS) has proven to be a useful tool for determining dissociation constants $\left(K_{\mathrm{d}}\right)$ for a variety of biological noncovalent complexes [26,27]. For covalent binders, a pseudo- $K_{\mathrm{d}}$ can be determined. It is measured in protein-ligand systems by calculating the electrospray-ion abundances of the free protein and the complexes [28]. Using the automated nanoESI-MS, the pseudo- $K_{\mathrm{d}}$ of altholactone and Rv1466 was measured by the titration approach using a constant Rv1466 concentration and titrating in the altholactone. Increasing the amount of ligand in the mixture results in the increased formation of the complex. The changes in the ratio of free Rv1466 to bound Rv1466 was used to calculate the pseudo- $K_{\mathrm{d}}$.

Figure 4 shows fourteen native mass spectra of samples containing $4.5 \mu \mathrm{M}$ Rv1466 and increasing concentrations of altholactone $(0.001-1000 \mu \mathrm{M})$. A ligand concentration was reached $(\sim 1000 \mu \mathrm{M})$ where the intensity of the protein-ligand complex reached a plateau. The ratios of the intensity of the protein-ligand peak and sum of protein peak plus protein-ligand peak were plotted against the concentration of altholactone (Figure 4). Using these ratios and Equations (1) and (2), a pseudo- $K_{\mathrm{d}}$ of $42.0 \pm 6.1 \mu \mathrm{M}$ was calculated for altholactone binding to Rv1466.

The structure of Rv1466 was solved by SSGCID using NMR-methods and the ensemble of structures can be accessed from the Protein Data Bank (5IRD). To assess the binding of altholactone to Rv1466, altholacone was docked onto the structure closest to the average structure in the ensemble of NMR structures, using the program PDB2PQR [29] via UnityMol [30] to prepare the structures at pH 6.9. AutoDock Vina [31] was used within Chimera [31] to predict non-covalent binding of the altholactone within the Rv1466 pocket. The structure shown in Figure 5 is the lowest energy structure with a score of $-6.7 \mathrm{kcal} / \mathrm{mol}$, a value that falls within a linear correlation between the predicted and experimental values, giving high confidence to the docking experiments [31]. As illustrated in Figure $5 \mathrm{~A}$, the docking program suggests that the altholactone bound to a pocket in the protein formed by a three-strand $\beta$-sheet and two parallel $\alpha$-helices. As shown in the surface rendition in Figure 5B, the altholactone bound deep inside this pocket. The mass spectrometry data suggests that a Ser, Thr, 
or Lys residue might form a covalent bond with the altholactone, and, as illustrated in Figure 5, the side chain of S9 sits close to the ligand where a reaction could occur.

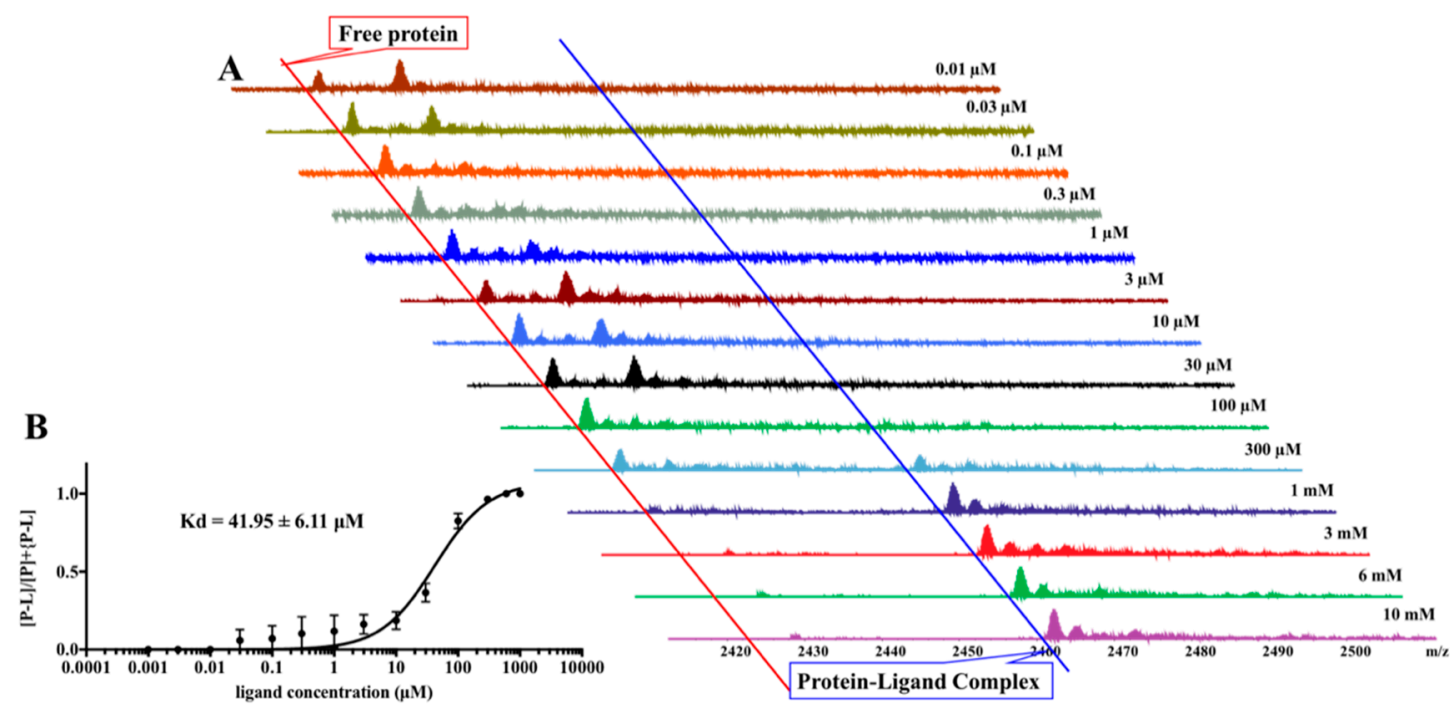

Figure 4. Determination of the pseudo- $K_{d}$ between altholactone and Rv1466. (A) Overlay of the 14 mass spectra of Rv1466 at a concentration of $4.5 \mu \mathrm{M}$ mixed with increasing concentration of pure altholactone $(0.001-1000 \mu \mathrm{M})$. (B) Plot of $[\mathrm{P}-\mathrm{L}] /[\mathrm{P}]+[\mathrm{P}-\mathrm{L}]$ versus ligand concentrations for the titration of Rv1466 with altholactone. The pseudo- $K_{\mathrm{d}}$ was calculated as $42.0 \pm 6.1 \mu \mathrm{M}$.

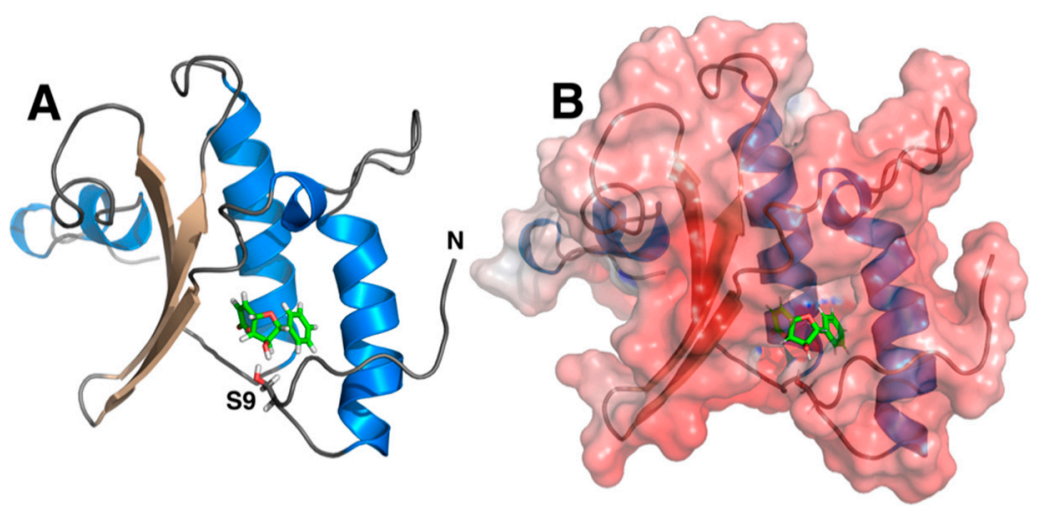

Figure 5. (A) Cartoon representation of the structure closest to the average structure of an ensemble of solution-state NMR structures calculated for Rv1466 (5IRD). Docking experiments show that the altholactone bound into a pocket formed by a three-strand $\beta$-sheet (pale) and two parallel $\alpha$-helices (blue). The atoms of the stick representation of altholactone are colored green (carbon), red (oxygen), and white (hydrogen). The side chain of a serine residue, S9, near the altholactone is highlighted. (B) Surface renditions of the single structure shown in Figure 5A with a stick representation of altholactone.

\section{Discussion}

In this work, a known compound altholactone was isolated from the plant Polyalthia sp. Altholactone has demonstrated anti-inflammatory and anticancer activities against eukaryotic tumor cells, and antifungal/antimicrobrial activity against both gram positive and negative bacteria [32-35], but the molecular mechanisms responsible were still not fully defined. Studies have also shown altholactone cytotoxicity against human HeLa cells with an $\mathrm{IC}_{50}$ of $148.7 \mu \mathrm{M}$ [23]. Mechanism studies reported that altholactone inhibited the growth of human bladder cancer $\mathrm{T} 24$ cells $\left(\mathrm{IC}_{50}=43.5 \mu \mathrm{M}\right)$ by inducing apoptosis [35] and induced DU145 cell death $\left(\mathrm{IC}_{50}=38.5 \mu \mathrm{M}\right)$, through inhibition of NF- $\mathrm{kB}$ and STAT3 activity [34]. 
In the current study, altholactone was shown to inhibit pathogenic $M t b$ and the fast growing non-pathogenic $M$. smegmatis, with MIC values of 64 and $500 \mu \mathrm{M}$, respectively. The lack of congruence between results obtained from the $M t b$ and $M$. smegmatis assay was observed and discussed extensively. While using M. smegmatis-based screens for anti-mycobacterial drug discovery remains well-recognized, an important limitation of $M$. smegmatis as a surrogate organism for $M t b$ drug discovery was sensitivity [36]. A significant number of molecules identified in $M t b$ assays did not show activity against $M$. smegmatis and, thus, would have been missed [37].

Retrospective analysis of a previous target screening study of a natural product fraction library against a panel of 37 Mycobacterium proteins by native MS identified a binding complex between Rv1466 and a ligand with a molecular weight of $232.06 \mathrm{Da}$. In the screening of 362 active fractions, only six fractions containing something that bound to Rv1466, ruling out the possibility of promiscuous small molecule binding to Rv1466. Further native MS experiments confirmed the ligand in one fraction as altholactone. Rv1466, along with proteins Rv1460 to Rv1465, comprise the primary Fe-S cluster assembly and repair SUF (mobilization of sulfur) machinery in $M t b$ [38]. Investigation of small molecule inhibitors of SUFs in various pathogenic models have been extensively conducted, such as D-cycloserine binding to Plasmodium falciparum SufS $(29.2 \pm 2.9 \mu \mathrm{M})$ [39], and VU0038882 binding to the Staphylococcus aureus iron-sulfur $(\mathrm{Fe}-\mathrm{S})$ cluster $(2.1 \mu \mathrm{M})$ [40]. A high-density mutagenesis study confirmed that six genes, Rv1461 to Rv1466, were required for in vitro mycobacterial growth [41]. It was reported that the SUF system plays an essential function for $M t b$ survival due to its role in providing bacterial resistance to iron limitation and oxidative stress [42]. Interruptions of individual proteins (Rv1461, Rv1462 or Rv1463) led to impeding mycobacterial growth [38], suggesting the high possibility that inhibiting a component of the multiprotein SUF complex would affect the whole SUF system, and eventually, lead to mycobacterial death.

Altholactone is likely to undergo an irreversible hetero-Michael addition reaction with an amino acid, such as serine, threonine, or lysine residue of Rv1466. Covalent inhibitors possess advantages such as enhanced biochemical efficiency, improved pharmacokinetics properties, and potential to overcome drug resistance $[43,44]$. While a protein-ligand complex between altholactone and Rv1466 was identified by our mass spectral assay that suggested a reaction with the side chain of a serine, threonine, or lysine group, the observation that none of the other 36 proteins in our screen reacted with the active fraction or pure altholactone suggests the compound does not react promiscuously with all proteins. Our molecular modelling indicates that a specific ligand binding pocket on the surface of Rv1466 exists where such a covalent reaction could occur. Further studies, including the use of Rv1466 knock-out strains of $M t b$, are necessary to confirm if inhibition of Rv1466 by altholactone is the mechanism of action.

Our findings support that altholactone could represent a novel chemotherapeutic natural agent or lead scaffold against tuberculosis. Since the concentration of altholactone required to inhibit mycobacterial species is rather high, more potent analogs of altholactone need to be developed for practical use in TB treatment.

\section{Materials and Methods}

\subsection{General Experimental Procedures}

NMR spectra for altholactone were recorded in DMSO- $d_{6}\left(\delta_{\mathrm{H}} 2.50\right.$ and $\left.\delta_{\mathrm{C}} 39.5\right)$ at $25{ }^{\circ} \mathrm{C}$ on a Bruker AVANCE III HDX 800 MHz NMR spectrometer (Fallanden, Zurich, Switzerland) equipped with a triple resonance cryoprobe. High-resolution electrospray ionization mass spectra (HRESIMS) were recorded on a Bruker maXis II ETD ESI- qTOF (Bruker, Bremen, Germany). The HPLC system for LLE fractions for phenotypic screening included a Waters 600 pump (Milford, MA, USA) fitted with a 996-photodiode array detector and Gilson FC204 fraction collector (Middleton, WI, USA). The HPLC system for purification of re-extracted material was a semi-preparative Thermo Ultimate 3000 system with a PDA detector (Waltham, MA, USA). A Phenomenex C18 Monolithic column 
$(5 \mu \mathrm{m}, 4.6 \times 100 \mathrm{~mm})$ was used for LLE fractionation; a Thermo Electron Betasil C18 column $(5 \mu \mathrm{m}$, $21.2 \times 150 \mathrm{~mm}$ ) was used for semi-preparative HPLC.

\subsection{Natural Product Fraction Library}

The lead-like enhanced natural product fraction library (202,983 fractions) was constructed as previously described [20].

\subsection{Phenotypic Screening against M. tuberculosis $\mathrm{H}_{37} \mathrm{Rv}$}

Growth inhibition of $M$. tuberculosis $\mathrm{H}_{37} \mathrm{Rv}$ using the natural product fraction library was conducted as previously reported [24]. Fractions were prepared from dried, ground biota, as previously described [20]. The terminology $250 \mu \mathrm{ge} / \mu \mathrm{L}$ meant the fraction originated from $250 \mu \mathrm{g}$ of dried, ground biota. Fractions were prepared to the concentration of $250 \mu \mathrm{ge} / \mu \mathrm{L}$ and growth inhibition of the $M$. tuberculosis strain $\mathrm{H}_{37} \mathrm{Rv}$ screening was monitored using $1 \mu \mathrm{L}$ fraction, followed by serial dilution in 384-well plates. To this, $40 \mu \mathrm{L}$ of $M$. tuberculosis ATCC $27294 \mathrm{H}_{37} \mathrm{Rv}\left(3-5 \times 10^{5} \mathrm{CFU} / \mathrm{mL}\right.$ in Middlebrook 7H9 broth with $0.05 \%$ Tween $80,10 \% v / v$ ADC and Casamino acids) was added with a Multidrop dispenser. The plates were then incubated at $37^{\circ} \mathrm{C}$ for 7 days. A $10 \mu \mathrm{L}$ solution of Resazurin (20 mg/100 mL diluted 1:1 with 10\% Tween 80) was added and incubated further for an additional $24 \mathrm{~h}$ at $37^{\circ} \mathrm{C}$ for color development. Absorbance was monitored at two wavelengths ( 575 and $610 \mathrm{~nm}$ ) using Spectramax and the ratios were determined to calculate the \% inhibition. Growth controls in the absence of compound as well as media controls served as inhibition $\sim 0 \%$ and $-100 \%$, respectively.

MIC - the least concentration which gave $\geq 80 \%$ inhibition was considered as MIC (start conc. $=1 \mu \mathrm{L}$ of fraction $(250 \mu \mathrm{ge} / \mu \mathrm{L})$.

\subsection{Re-Extraction and Purification}

Freeze-dried Polyalthia sp. (10.0 g) was sequentially extracted with $n$-hexane $(250 \mathrm{~mL}), \mathrm{CH}_{2} \mathrm{Cl}_{2}(250 \mathrm{~mL})$, and $\mathrm{MeOH}(2 \times 250 \mathrm{~mL})$. The $\mathrm{CH}_{2} \mathrm{Cl}_{2}$ and $\mathrm{MeOH}$ extracts were combined and dried under reduced pressure, to yield a dark brown solid $(1.50 \mathrm{~g})$. The plant crude extract was pre-adsorbed to a roll of cotton and then packed into a stainless-steel cartridge $(10 \times 30 \mathrm{~mm})$ that was subsequently attached to a C18 Betasil HPLC column $(250 \times 21.2 \mathrm{~mm})$. Isocratic HPLC conditions of $90 \% \mathrm{H}_{2} \mathrm{O}(0.1 \% \mathrm{TFA}) / 10 \% \mathrm{MeOH}$ $(0.1 \% \mathrm{TFA})$ were employed for the first $10 \mathrm{~min}$, and then a linear gradient to $\mathrm{MeOH}(0.1 \% \mathrm{TFA})$ was run over $60 \mathrm{~min}$, followed by isocratic conditions of $\mathrm{MeOH}(0.1 \% \mathrm{TFA})$, for a further $10 \mathrm{~min}$, all at a flow rate of $9 \mathrm{~mL} / \mathrm{min}$. Sixty fractions $(60 \times 1 \mathrm{~min})$ were collected from the start of the HPLC run. The ${ }^{1} \mathrm{H}$ NMR $800 \mathrm{MHz}$ fingerprints of fraction 30 compared to the ${ }^{1} \mathrm{H}$ NMR of the active fraction confirmed the presence of altholactone (10 $\mathrm{mg}$, dry weight).

\subsection{Altholactone}

Brown solid; HRMS $m / z 255.0623[\mathrm{M}+\mathrm{Na}]^{+}, m / z$ 487.1353 [2M + Na $]^{+}$, calcd. MW for 232.0623. ${ }^{1} \mathrm{H}$ NMR (DMSO- $\left.d_{6}, 800 \mathrm{MHz}\right) \delta_{\mathrm{H}} 7.34\left(2 \mathrm{H}, \mathrm{m}, \mathrm{H}-3^{\prime}, 5^{\prime}\right), 7.28\left(3 \mathrm{H}, \mathrm{m}, \mathrm{H}-2^{\prime}, 4^{\prime}, 6^{\prime}\right), 7.13(1 \mathrm{H}, \mathrm{dd}, \mathrm{J}=9.8$, $4.9 \mathrm{~Hz}, \mathrm{H}-7), 6.20(1 \mathrm{H}, \mathrm{d}, \mathrm{J}=9.8 \mathrm{~Hz}, \mathrm{H}-6), 4.89(1 \mathrm{H}, \mathrm{dd}, \mathrm{J}=5.0,2.2 \mathrm{~Hz}, \mathrm{H}-4), 4.67(1 \mathrm{H}, \mathrm{d}, \mathrm{J}=4.9 \mathrm{~Hz}$, $\mathrm{H}-2), 4.64(1 \mathrm{H}, \mathrm{t}, \mathrm{J}=5.2 \mathrm{~Hz}, \mathrm{H}-8), 4.11(1 \mathrm{H}, \mathrm{dd}, \mathrm{J}=5.2,2.2 \mathrm{~Hz}, \mathrm{H}-3) ;{ }^{13} \mathrm{C}$ NMR (DMSO-d 6 , $\left.200 \mathrm{MHz}\right) \delta_{\mathrm{C}}$ $160.97(\mathrm{CO}), 141.32(\mathrm{CH}, \mathrm{C} 7), 139.53(\mathrm{C}, \mathrm{C} 1), 128.36\left(\mathrm{CH}, \mathrm{C}^{\prime}, 5^{\prime}\right), 127.72\left(\mathrm{CH}, \mathrm{C} 4^{\prime}\right), 125.88\left(\mathrm{CH}, \mathrm{C}^{\prime}, 6^{\prime}\right)$, $123.11(\mathrm{CH}, \mathrm{C} 6), 85.88(\mathrm{CH}, \mathrm{C} 2), 85.78(\mathrm{CH}, \mathrm{C} 4), 83.02(\mathrm{CH}, \mathrm{C} 3), 67.97(\mathrm{CH}, \mathrm{C} 8)$.

\subsection{Biological Assays}

Altholactone was evaluated for its anti-mycobacterial activities against the M. smegmatis strain $\mathrm{mc}^{2} 155$ (ATCC 70084) and M. tuberculosis $\mathrm{mc}^{2} 6230$. The M. smegmatis strain $\mathrm{mc}^{2} 155$ was grown in Middle brook 7H9 broth (Difco, Sparks, MD, USA) supplemented with 10\% (v/v) OADC enrichment (Becton Dickinson) $0.05 \%(v / v)$ Tween-80 and $0.2 \%(v / v)$ glycerol. Cultures were grown at $37{ }^{\circ} \mathrm{C}$, while shaking (200 rpm). In clear-bottomed 96 -well plates (Nunc), two-fold serial dilutions (8 times) of 
each compound were added to volumes of $40 \mu \mathrm{L}$ of $7 \mathrm{H} 9$ medium. The last column of each plate did not contain any compound and served as a negative control. Previously prepared M. smegmatis strain $\mathrm{mc}^{2} 155$ inocula were diluted with their culture medium to achieve $0.0025 \mathrm{OD}_{600}$. Isoniazid served as a positive control and DMSO as a negative control. The plate was incubated at $37^{\circ} \mathrm{C}$ for $24 \mathrm{~h}$. After incubation, $30 \mu \mathrm{L}$ of $0.02 \%$ resazurin was added to the wells, and the plates were incubated at $37^{\circ} \mathrm{C}$ for $4 \mathrm{~h}$. The minimal inhibitory concentration was determined by the compound concentration well that remained blue and did not change to pink. All experiments were performed in triplicates.

The M. tuberculosis strain $\mathrm{mc}^{2} 6230$ used in this study was obtained from the Howard Hughes Medical Institute, Department of Microbiology and Immunology, Albert Einstein College of Medicine. Mycobacterial strains were grown in Middlebrook 7H9 medium (Difco, Sparks, MD, USA) supplemented with 10\% (v/v) OADC enrichment (Difco), 0.2\% (v/v) glycerol, 0.05\% (v/v) tyloxapol, and pantothenate $(50 \mathrm{mg} / \mathrm{L})$. Cultures were grown at $37^{\circ} \mathrm{C}$, while shaking $(160 \mathrm{rpm})$. In clear-bottomed 96-well plates (Nunc), two-fold serial dilutions (8 times) of each compound were added to volumes of $100 \mu \mathrm{L}$ of 7H9 medium. The last column of each plate did not contain any compound and served as a negative control. Previously prepared $M t b \mathrm{mc}^{2} 6230$ inocula were diluted with their respected medium to achieve $0.05 \mathrm{OD}_{600}$. The inocula were then added to each well and the plates were incubated at $37^{\circ} \mathrm{C}$ for five days. After incubation, $30 \mu \mathrm{L}$ of $0.02 \%$ resazurin was added to the wells, and the plates were incubated at $37^{\circ} \mathrm{C}$ for $24 \mathrm{~h}$. The minimal inhibitory concentration was determined by the compound concentration well that remained blue and did not change to pink. All experiments were performed in triplicates.

\subsection{Target Screening}

Rv1466 and the other 36 unique proteins (Figure 6) in the target panel were supplied by the Seattle Structural Genomics Center for Infectious Diseases (SSGCID, Seattle, WA, USA; www.ssgcid.org). Target screening of the pool fraction library against the protein panel was conducted as previously reported [24]. When the protein-ligand complex was found, the molecular weight of the binding ligand was estimated from the spectrum, using the following equation: MW ligand $=\Delta m / z \times z$.

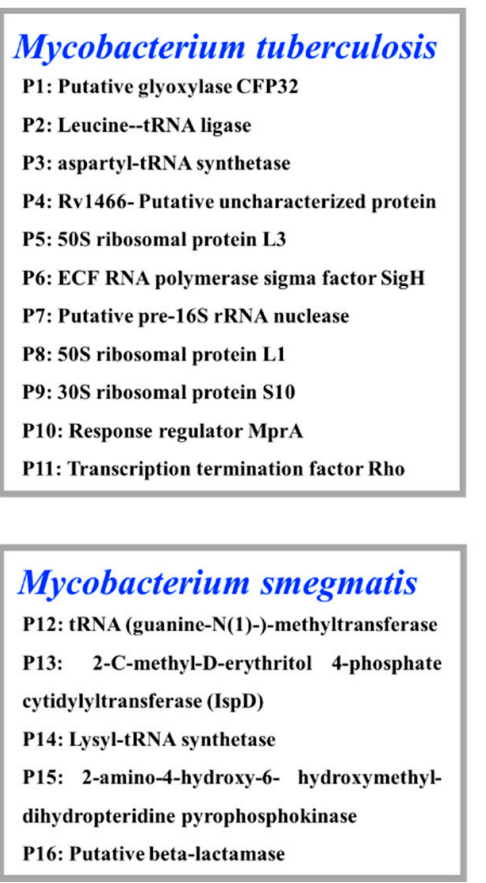

\section{Mycobacterium leprae \\ P17: Ribonuclease 3 \\ P18: Methionine--tRNA ligase \\ P19: Aspartyl-tRNA synthetase}

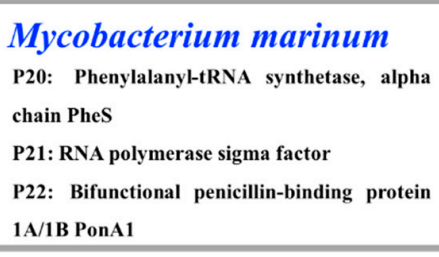

1A/1B PonA1

\begin{tabular}{l} 
Mycobacterium ulcerans \\
P23: RNA polymerase sigma factor \\
P24: Lysyl-tRNA synthetase \\
P25: Dihydrofolate reductase (DHFR) \\
\hline Mycobacterium fotuitum \\
P26: RNA polymerase sigma factor \\
P27: RNA polymerase sigma factor SigF \\
P28: 2-amino-4-hydroxy-6- hydroxymethyl- \\
dihydropteridine pyrophosphokinase
\end{tabular}

\section{Mycobacterium abscessus}

P29: Phenylalanyl-tRNA synthetase alpha chain PheS P30: tRNA (guanine-N(1)-)-methyltransferase P31: Ribosomal RNA small subunit methyltransferase $G$

P32: Probable 4-diphosphocytidyl-2-Cmethyl-D-erythritol kinase (IspE) P33: Putative beta-lactamase

\section{Mycobacterium avium}

P34: putative beta-lactamase

P35: 2-amino-4-hydroxy-6- hydroxymethyldihydropteridine pyrophosphokinase

\section{Mycobacterium} paratuberculosis

P36: tRNA (guanine-N(1)-)-methyltransferase P37: RNA polymerase sigma factor

Figure 6. List of the collection of 37 TB proteins from nine Mycobacteria species. 


\subsection{Pseudo-K $K_{d}$ Determination}

Altholactone solutions were prepared in DMSO through serial dilution $(0.01 \mu \mathrm{M}, 0.03 \mu \mathrm{M}, 0.1 \mu \mathrm{M}$, $0.3 \mu \mathrm{M}, 1 \mu \mathrm{M}, 3 \mu \mathrm{M}, 10 \mu \mathrm{M}, 30 \mu \mathrm{M}, 100 \mu \mathrm{M}, 300 \mu \mathrm{M}, 1 \mathrm{mM}, 3 \mathrm{mM}, 6 \mathrm{mM}, 10 \mathrm{mM})$. Each concentration $(1 \mu \mathrm{L})$ was added to each well of a V-plate microtiter plate (BioCentrix, Carlsbad, CA, USA). The DMSO in each well was dried off using a Freeze dryer (Christ, Osterode am Harz, Germany), followed by the addition of $1 \mu \mathrm{L}$ of $\mathrm{MeOH}$ to each well. Rv1466 was buffer-exchanged into ammonium acetate (500 mM, pH 6.9) using a Nalgene NAP-5 exclusion column, prior to ESI-MS analysis. Rv1466 (9 $\mu \mathrm{L})$ was added to each well containing the altholactone. Samples were incubated for 30 to $60 \mathrm{~min}$ at room temperature. All sample solutions were injected by fully automated chip-based nanoelectrospray. The experiment was performed in triplicate.

The relative abundances of the protein-ligand complex to total protein in the mass spectra correlated to the relative equilibrium concentrations of the ligand to the total protein in solution. The pseudo- $K_{\mathrm{d}}$ of altholactone with Rv1466 was determined using the following equations:

$$
\begin{gathered}
\frac{\sum I(P-L)^{n+} / n}{\sum I(P)^{n+} / n+\sum I(P-L)^{n+} / n}=\frac{[P-L]}{[P]_{t}} \\
\frac{\sum I(P-L)^{n+} / n}{\sum I(P)^{n+} / n+\sum I(P-L)^{n+} / n}=\frac{[P]_{t}+[L]_{t}+\mathrm{Kd}-\sqrt{\left.\left([P]_{t}+[L]_{t}+K_{d}\right)^{2}-4[P]_{t}[L]_{t}\right)}}{2[P]_{t}}
\end{gathered}
$$

Experimental relative ratios of the protein-ligand complex and total protein ion abundances were plotted against the total concentration of ligand.

Author Contributions: Conceptualization, M.L. and R.J.Q.; methodology, A.R.E., D.G., J.H., Y.F., A.D.C., T.M., J.A.L., G.W.B., P.J.M., and G.C.; resources, M.L. and R.J.Q.; data curation, M.L.; writing-original draft preparation, A.R.E. and M.L.; writing-review and editing, M.L., R.J.Q. and G.W.B. All authors have read and agreed to the published version of the manuscript.

Funding: This research was funded by the Bill and Melinda Gates Foundation (OPP1035218, OPP1174957) with additional support from the Australian Research Council Discovery and Linkage Projects (DP160101429, LP120100485, LE120100170 (equipment), LE140100119 (equipment)), and the National Institute of Allergy and Infectious Diseases, National Institutes of Health, Department of Health and Human Services (Federal Contract numbers HHSH27220120025C, HHSN272200700057C, and HHSN272201700059C).

Acknowledgments: We acknowledge the NatureBank biota repository that is housed at the Griffith Institute for Drug Discovery at Griffith University (www.griffith.edu.au/gridd). We thank Vasanthi Ramachandran, Sreevalli Sharma, Supreeth Guptha, and Sunita DeSousa (formerly at AstraZeneca Bangalore) for the M. tuberculosis H37Rv assay. Part of the research was conducted at the W.R. Wiley Environmental Molecular Sciences Laboratory, a national scientific user facility sponsored by U.S. Department of Energy's Office of Biological and Environmental Research (BER) program located at Pacific Northwest National Laboratory (PNNL). Battelle operates PNNL for the U.S. Department of Energy.

Conflicts of Interest: The authors declare no conflict of interest.

\section{References}

1. World Health Organization. Global Tuberculosis Report 2019; World Health Organization: Geneva, Switzerland, 2019; Licence: CC BY-NC-SA 3.0 IGO.

2. Blaser, M.J.; Kirschner, D. The equilibria that allow bacterial persistence in human hosts. Nature 2007, 449, 843-849. [CrossRef] [PubMed]

3. Russell, D.G.; Barry, C.E.; Flynn, J.L. Tuberculosis: What we don't know can, and does, hurt us. Science 2010, 328, 852-856. [CrossRef] [PubMed] 
4. Han, J.Y.; Zhang, J.Y.; Song, Z.J.; Liu, M.M.; Hu, J.S.; Hou, C.J.; Zhu, G.L.; Jiang, L.; Xia, X.K.; Quinn, R.J.; et al. Genome- and MS-based mining of antibacterial chlorinated chromones and xanthones from the phytopathogenic fungus Bipolaris sorokiniana strain 11134. Appl. Microbiol. Biot. 2019, 103, 5167-5181. [CrossRef] [PubMed]

5. Liu, M.M.; Abdel-Mageed, W.M.; Ren, B.; He, W.N.; Huang, P.; Li, X.L.; Bolla, K.; Guo, H.; Chen, C.X.; Song, F.H.; et al. Endophytic Streptomyces sp Y3111 from traditional Chinese medicine produced antitubercular pluramycins. Appl. Microbiol. Biot. 2014, 98, 1077-1085. [CrossRef] [PubMed]

6. Liu, M.M.; El-Hossary, E.M.; Oelschlaeger, T.A.; Donia, M.S.; Quinn, R.J.; Abdelmohsen, U.R. Potential of marine natural products against drug-resistant bacterial infections. Lancet Infect. Dis. 2019, 19, 237-245. [CrossRef]

7. Newman, D.J.; Cragg, G.M. Natural products as sources of new drugs from 1981 to 2014. J. Nat. Prod. 2016, 79, 629-661. [CrossRef]

8. Harvey, A.L.; Edrada-Ebel, R.; Quinn, R.J. The re-emergence of natural products for drug discovery in the genomics era. Nat. Rev. Drug. Discov. 2015, 14, 111-129. [CrossRef]

9. Cragg, G.M.; Newman, D.J. Natural products: A continuing source of novel drug leads. Biochim. Biophys. Acta 2013, 1830, 3670-3695. [CrossRef]

10. Marques, A.; Martins, I.S.; Kastner, T.; Plutzar, C.; Theurl, M.C.; Eisenmenger, N.; Huijbregts, M.A.J.; Wood, R.; Stadler, K.; Bruckner, M.; et al. Increasing impacts of land use on biodiversity and carbon sequestration driven by population and economic growth. Nat. Ecol. Evol. 2019, 3, 628-637. [CrossRef]

11. Daskin, J.H.; Pringle, R.M. Warfare and wildlife declines in Africa's protected areas. Nature 2018, 553, 328-332. [CrossRef]

12. Parmesan, C. Ecological and evolutionary responses to recent climate change. Annu. Rev. Ecol. Evol. Syst. 2006, 37, 637-669. [CrossRef]

13. Cardinale, B.J.; Duffy, J.E.; Gonzalez, A.; Hooper, D.U.; Perrings, C.; Venail, P.; Narwani, A.; Mace, G.M.; Tilman, D.; Wardle, D.A. Biodiversity loss and its impact on humanity. Nature 2012, 486, 59-67. [CrossRef] [PubMed]

14. Pan, S.J.; Zhang, H.L.; Wang, C.Y.; Yao, S.C.L.; Yao, S.Q. Target identification of natural products and bioactive compounds using affinity-based probes. Nat. Prod. Rep. 2016, 33, 612-620. [CrossRef] [PubMed]

15. Yoshida, M. Recent advances in target identification of bioactive natural products. Biosci. Biotechnol. Biochem. 2019, 83, 1-9. [CrossRef] [PubMed]

16. Schenone, M.; Dancik, V.; Wagner, B.K.; Clemons, P.A. Target identification and mechanism of action in chemical biology and drug discovery. Nat. Chem. Biol. 2013, 9, 232-240. [CrossRef]

17. Carver, T.E.; Bordeau, B.; Cummings, M.D.; Petrella, E.C.; Pucci, M.J.; Zawadzke, L.E.; Dougherty, B.A.; Tredup, J.A.; Bryson, J.W.; Yanchunas, J.J.; et al. Decrypting the biochemical function of an essential gene from Streptococcus pneumoniae using thermofluor technology. J. Biol. Chem. 2005, 280, 11704-11712. [CrossRef]

18. Pedro, L.; Quinn, R.J. Native mass spectrometry in fragment-based drug discovery. Molecules 2016, $21,984$. [CrossRef]

19. Vu, H.; Quinn, R.J. Direct screening of natural product extracts using mass spectrometry. J. Biomol. Screen. 2008, 13, 265-275. [CrossRef]

20. Camp, D.; Davis, R.A.; Campitelli, M.; Ebdon, J.; Quinn, R.J. Drug-like properties: Guiding principles for the design of natural product libraries. J. Nat. Prod. 2012, 75, 72-81. [CrossRef]

21. Loder, J.W.; Nearn, R.H. Altholactone, a novel tetrahydrofuro[3,2b]pyran-5-one from a polyalthia species (Annonaceae). Heterocycles 1977, 7, 113-118. [CrossRef]

22. Lekphrom, R.; Kanokmedhakul, S.; Kanokmedhakul, K. Bioactive styryllactones and alkaloid from flowers of Goniothalamus laoticus. J. Ethnopharmacol. 2009, 125, 47-50. [CrossRef] [PubMed]

23. Macabeo, A.P.G.; Lopez, A.D.A.; Schmidt, S.; Heilmann, J.; Dahse, H.M.; Alejandro, G.J.D.; Franzblau, S.G. Antitubercular and cytotoxic constituents from Goniothalamus gitingensis. Rec Nat. Prod. 2014, 8, 41-45. 
24. Xie, Y.; Feng, Y.; Di Capua, A.; Mak, T.; Buchko, G.W.; Myler, P.J.; Liu, M.; Quinn, R.J. A phenotarget approach for identifying an alkaloid interacting with the tuberculosis protein Rv1466. Mar. Drugs 2020, 18, 149. [CrossRef] [PubMed]

25. Vu, H.; Pedro, L.; Mak, T.; McCormick, B.; Rowley, J.; Liu, M.M.; Di Capua, A.; Williams-Noonan, B.; Pham, N.B.; Pouwer, R.; et al. Fragment-based screening of a natural product library against 62 potential malaria drug targets employing native mass spectrometry. ACS Infect. Dis. 2018, 4, 431-444. [CrossRef] [PubMed]

26. Yang, B.; Feng, Y.J.; Vu, H.; McCormick, B.; Rowley, J.; Pedro, L.; Crowther, G.J.; Van Voorhis, W.C.; Forster, P.I.; Quinn, R.J. Bioaffinity mass spectrometry screening. J. Biomol. Screen. 2016, 21, 194-200. [CrossRef] [PubMed]

27. Zhang, S.; Van Pelt, C.K.; Wilson, D.B. Quantitative determination of noncovalent binding interactions using automated nanoelectrospray mass spectrometry. Anal. Chem. 2003, 75, 3010-3018. [CrossRef]

28. Pedro, L.; Van Voorhis, W.C.; Quinn, R.J. Optimization of electrospray ionization by statistical design of experiments and response surface methodology: Protein-ligand equilibrium dissociation constant determinations. J. Am. Soc. Mass Spectr. 2016, 27, 1520-1530. [CrossRef]

29. Dolinsky, T.J.; Nielsen, J.E.; McCammon, J.A.; Baker, N.A. PDB2PQR: An automated pipeline for the setup of Poisson-Boltzmann electrostatics calculations. Nucleic Acids Res. 2004, 32, 665-667. [CrossRef]

30. Laureanti, J.A.; Brandi, J.; Offor, E.; Engel, D.; Rallo, R.; Ginovska, B.; Martinez, X.; Baaden, M.; Baker, N.A. Visualizing biomolecular electrostatics in virtual reality with UnityMol-APBS. Protein Sci. 2019, 29, 237-246. [CrossRef]

31. Trott, O.; Olson, A.J. Software news and update Autodock Vina: Improving the speed and accuracy of docking with a new scoring function, efficient optimization, and multithreading. J. Comput. Chem. 2010, 31, 455-461.

32. Al Momani, F.; Alkofahi, A.S.; Mhaidat, N.M. Altholactone displays promising antimicrobial activity. Molecules 2011, 16, 4560-4566. [CrossRef] [PubMed]

33. Euanorasetr, J.; Junhom, M.; Tantimavanich, S.; Vorasin, O.; Munyoo, B.; Tuchinda, P.; Panbangred, W. Halogenated benzoate derivatives of altholactone with improved anti-fungal activity. J. Asian Nat. Prod. Res. 2016, 18, 462-474. [CrossRef] [PubMed]

34. Jiang, C.W.; Masood, M.; Rasul, A.; Wei, W.; Wang, Y.; Ali, M.; Mustaqeem, M.; Li, J.; Li, X.M. Altholactone Inhibits NF-kappa B and STAT3 activation and induces reactive oxygen species-mediated apoptosis in prostate cancer DU145 cells. Molecules 2017, 22, 240. [CrossRef]

35. Zhao, B.; Li, X.M. Altholactone induces reactive oxygen species-mediated apoptosis in bladder cancer T24 cells through mitochondrial dysfunction, MAPK-p38 activation and Akt suppression. Oncol. Rep. 2014, 31, 2769-2775. [CrossRef] [PubMed]

36. Forbes, L.; Ebsworth-Mojica, K.; DiDone, L.; Li, S.G.; Freundlich, J.S.; Connell, N.; Dunman, P.M.; Krysan, D.J. A high throughput screening assay for anti-Mycobacterial small molecules based on adenylate kinase release as a reporter of cell lysis. PLoS ONE 2015, 10, e0129234. [CrossRef] [PubMed]

37. Altaf, M.; Miller, C.H.; Bellows, D.S.; O'Toole, R. Evaluation of the Mycobacterium smegmatis and BCG models for the discovery of Mycobacterium tuberculosis inhibitors. Tuberculosis 2010, 90, 333-337. [CrossRef] [PubMed]

38. Huet, G.; Daffe, M.; Saves, I. Identification of the Mycobacterium tuberculosis SUF machinery as the exclusive mycobacterial system of [Fe-S] cluster assembly: Evidence for its implication in the pathogen's survival. J. Bacteriol 2005, 187, 6137-6146. [CrossRef]

39. Charan, M.; Singh, N.; Kumar, B.; Srivastava, K.; Siddiqi, M.I.; Habib, S. Sulfur mobilization for Fe-S cluster assembly by the essential SUF pathway in the Plasmodium falciparum apicoplast and its inhibition. Antimicrob. Agents Chemother. 2014, 58, 3389-3398. [CrossRef]

40. Choby, J.E.; Mike, L.A.; Mashruwala, A.A.; Dutter, B.F.; Dunman, P.M.; Sulikowski, G.A.; Boyd, J.M.; Skaar, E.P. A small-molecule inhibitor of iron-sulfur cluster assembly uncovers a link between virulence regulation and metabolism in Staphylococcus aureus. Cell Chem. Biol. 2016, 23, 1351-1361. [CrossRef]

41. Sassetti, C.M.; Boyd, D.H.; Rubin, E.J. Genes required for mycobacterial growth defined by high density mutagenesis. Mol. Microbiol. 2003, 48, 77-84. [CrossRef] 
42. Willemse, D.; Weber, B.; Masino, L.; Warren, R.M.; Adinolfi, S.; Pastore, A.; Williams, M.J. Rv1460, a SufR homologue, is a repressor of the suf operon in Mycobacterium tuberculosis. PLoS ONE 2018, 13, e0200145. [CrossRef] [PubMed]

43. Jackson, P.A.; Widen, J.C.; Harki, D.A.; Brummond, K.M. Covalent modifiers: A chemical perspective on the reactivity of alpha, beta-unsaturated carbonyls with thiols via hetero-Michael addition reactions. J. Med. Chem. 2017, 60, 839-885. [CrossRef] [PubMed]

44. Wang, L.H.; Zhao, J.Y.; Yao, Y.; Wang, C.Y.; Zhang, J.B.; Shu, X.H.; Sun, X.L.; Li, Y.X.; Liu, K.X.; Yuan, H.; et al. Covalent binding design strategy: A prospective method for discovery of potent targeted anticancer agents. Eur. J. Med. Chem. 2017, 142, 493-505. [CrossRef] [PubMed]

Sample Availability: Samples of the compounds altholactone and protein Rv1466 are available from the authors.

(C) 2020 by the authors. Licensee MDPI, Basel, Switzerland. This article is an open access article distributed under the terms and conditions of the Creative Commons Attribution (CC BY) license (http://creativecommons.org/licenses/by/4.0/). 